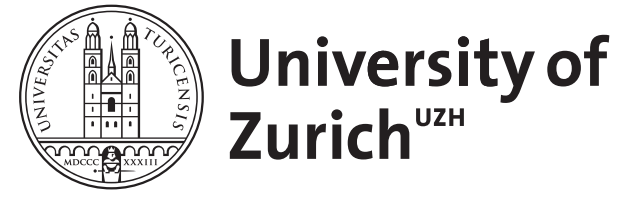
Archive

University of Zurich

University Library

Strickhofstrasse 39

CH-8057 Zurich

www.zora.uzh.ch

Year: 2013

\title{
Erythrocytosis: the HIF pathway in control
}

Franke, Kristin ; Gassmann, M ; Wielockx, B

DOI: https://doi.org/10.1182/blood-2013-01-478065

Posted at the Zurich Open Repository and Archive, University of Zurich

ZORA URL: https://doi.org/10.5167/uzh-78919

Journal Article

Accepted Version

Originally published at:

Franke, Kristin; Gassmann, M; Wielockx, B (2013). Erythrocytosis: the HIF pathway in control. Blood, 122(7):1122-1128.

DOI: https://doi.org/10.1182/blood-2013-01-478065 


\title{
Review Article
}

\section{Blood 2013, in press}

\section{Erythrocytosis - the HIF Pathway in Control}

\author{
Kristin Franke ${ }^{1}$, Max Gassmann ${ }^{2,3}$ and Ben Wielockx ${ }^{1,4}$
}

${ }^{1}$ Emmy Noether Research Group, Institute of Pathology, University of Technology, Dresden, Germany. ${ }^{2}$ Institute of Veterinary Physiology, Vetsuisse Faculty and Zurich Center for Integrative Human Physiology (ZIHP). ${ }^{3}$ Universidad Peruana Cayetano Heredia (UPCH), Lima, Peru. ${ }^{4}$ DFG Research Center and Cluster of Excellence for Regenerative Therapies Dresden, University of Technology, Dresden, Germany.

Address correspondence to: Ben Wielockx, Emmy Noether group (DFG) Inst. of Pathology University of Technology Dresden, Schubertstrasse 15, D-01307 Dresden, Germany; Tel: +49-351 4585257; Fax: +49-351 4584328; Ben.Wielockx@uniklinikum-dresden.de

Running title: HIF2 $\alpha$, PHD2 and VHL in erythrocytosis

Keywords: hypoxia, erythropoietin 


\begin{abstract}
Organisms living under aerobic conditions need oxygen for the metabolic conversion of nutrition into energy. With the appearance of increasingly complex animals, a specialized transport system (erythrocytes) arose during evolution in order to provide oxygen to virtually every single cell in the body. Moreover, in case of low environmental $\mathrm{pO}_{2}$ the number of erythrocytes automatically increases to preserve sustained oxygen delivery. This process relies predominantly on the cytokine erythropoietin (EPO) and its transcription factor hypoxia inducible factor (HIF), whereas the von Hippel Lindau (VHL) ubiquitin ligase as well as the oxygen-sensitive prolyl hydroxylases (PHDs) represent essential regulators of this oxygensensing system. Deregulation of particular members of this pathway (e.g. PHD2, HIF2 $\alpha$ and VHL) lead to disorders in blood homeostasis due to insufficient (anemia) or excessive (erythrocytosis) red blood cell production.
\end{abstract}




\section{Introduction}

High altitude is accompanied by low atmospheric oxygen pressure, which sequentially leads to insufficient oxygen uptake and reduced tissue oxygenation. In general, inadequate oxygen supply is detrimental and might lead to death of cells, tissues or ultimately even the organism. In order to avoid this complex cardiovascular, respiratory and hematological mechanisms have evolved, and one such long-term adaptation process is the elevation of erythrocyte numbers to boost the blood's oxygen transport capacity.

As early as in the 19th century, scientists recognized the correlation between low atmospheric oxygen pressure and elevated red blood cell numbers in humans and animals. ${ }^{1}$ Some decades later, it became evident that low oxygen does not directly act on hematopoietic cells but induces the production of a soluble factor called erythropoietin (EPO). In 1977, EPO was purified from the urine of anemic patients ${ }^{2}$ and in 1985 the corresponding EPO gene was isolated and cloned. ${ }^{3}$ About two decades ago, the transcription factor HIF (hypoxia inducible factor) was first identified in hepatoma cells as the regulator of EPO through its binding to a hypoxia responsive element (HRE) present in the 3 'enhancer region of the EPO gene. ${ }^{4,5}$ In subsequent work, HIF was found to be expressed widespread in mammalian cells and even in lower animals that do not produce Epo or red blood cells. ${ }^{6-8}$ In the past decennium a lot of knowledge has been acquired on the role of HIFs during red blood cell production (erythropoiesis). Accordingly, this review aims to discuss recent findings on these essential proteins in humans and mice, and the detrimental impact of their deregulation.

\section{Erythropoietin: the driving force of erythropoiesis}


EPO, a glycoprotein hormone, is the principal stimulator of erythropoiesis and is induced under hypoxic conditions. In 1957, the kidney was first identified as the primary EPO producing organ in adult mammals, ${ }^{9}$ whereas the liver is the major source of EPO during embryogenesis (e.g. hepatocytes, Ito cells). In the kidney, a specialized EPO-producing cell (REPC) was identified in the cortex and outer medulla that was initially described as an interstitial fibroblast-like cell with neuronal characteristics. ${ }^{10-14}$ Interestingly and in contrast to other organs, the kidney is able to increase the total amount of REPCs in an oxygendependent manner rather than increasing EPO expression per cell. ${ }^{11,14}$ Neurons and glial cells in the central nervous system (CNS) represent an additional source of $\mathrm{EPO}^{15,16}$, it has been suggested that the glycohormone functions in a paracrine fashion as a protective, ${ }^{17}$ ventilations ${ }^{18}$ or cognition-enhancing factor. ${ }^{19}$

Erythropoiesis is a complex multistep process during which erythroid progenitors enucleate and develop into mature red blood cells. Upon Epo binding to its receptor, the EpoR signaling through the Janus kinase 2 (JAK2) activates multiple pathways including Stat5, phosphoinositide-3 kinase (PI-3K)/Akt, and p42/44 mitogen-activated protein kinase (MAPK). This reduces apoptosis and promotes expansion and differentiation of the progenitors. ${ }^{20}$ In adult mammals, erythropoiesis is mainly carried out by the bone marrow. However, in response to stress (e.g. anemia / bone marrow transfer / certain diseases), erythropoiesis may extend to extramedullary sites, such as spleen and liver, thereby increasing erythrocyte output. As shown in mice, stress erythropoiesis is characterized by massive selfrenewal of BFU-E (burst-forming unit-erythroid) cells and is regulated by additional extrinsic factors like the stress hormone cortisol, stem cell factor (SCF) and the bone morphogenetic protein 4 (BMP4). ${ }^{21-24}$ In humans, analogous pathways have not yet been identified, and the molecular basis is also not well described. However, recently, erythroblastic island macrophages have been reported to facilitate human stress and pathological erythropoiesis. ${ }^{25}$ 


\section{The HIF pathway}

The HIF pathway is present in virtually every cell of the body, orchestrating a whole cascade of downstream genes that allow acclimatization to reduced levels of oxygen. The alpha subunit of the HIFs (mainly HIF1 $\alpha$ and HIF $2 \alpha$ ) becomes stabilized nearly instantaneously during low oxygen conditions ${ }^{26}$ and translocates to the nucleus where it dimerises with the constitutively expressed HIF $\beta$ subunit and promotes transcription of genes containing a HRE ${ }^{27}$ In human cells, pan-genomic analyses of HIF binding to DNA have now revealed the existence of more than 500 direct transcriptional targets of HIF in a given cell line. ${ }^{28,29}$ More than a decade ago, the groups of Dr. Ratcliffe and Dr. Kaelin discovered that both HIF1 $\alpha$ and HIF $2 \alpha$ are regulated at the post-transcriptional level by the HIF prolyl-hydroxylase domain enzymes (PHDs). These oxygen sensors hydroxylate the alpha-subunits and prime them for poly-ubiquitination by the von Hippel-Lindau (VHL) tumor suppressor complex which ultimately leads to proteolytic degradation (Figure 1). ${ }^{30,31}$ To date, four PHDs have been identified in mammals, of which PHD2 (gene name: Egl nine homolog 1 (Egln1)) has been described as the key limiting enzyme targeting HIF $\alpha$ for degradation under normoxic and mild hypoxic conditions. ${ }^{32-34}$

HIF $1 \alpha$ exhibits a ubiquitous expression pattern whereas HIF $2 \alpha$ is found in a limited number of cell types including endothelial cells, cardiomyocytes, hepatocytes, glial cells and interstitial cells of the kidney. ${ }^{35}$ Both isoforms have overlapping sets of target genes, but can also play non-redundant roles, depending on the cell type and oxygen concentrations. ${ }^{36}$ Accordingly, HIF $1 \alpha$ has been suggested to represent the response to acute hypoxia, while HIF $2 \alpha$ is the predominant subunit to chronic exposure to low oxygen as occurring at high altitude. ${ }^{37}$ In addition, several studies have demonstrated that both HIF isoforms can even display opposing roles in vivo, for instance in renal cell carcinoma growth and metastasis 
formation. ${ }^{38,39}$ Glycolysis enzymes like phosphoglycerate kinase 1 (PGK1) and lactate dehydrogenase A (LDHA) are predominantly HIF1 $\alpha$-dependent. ${ }^{36}$ In contrast, HIF2 $\alpha$ has been described to induce matrix metallopeptidase 9 (MMP9) and the transcription factor oct4, that is involved in stem cell function and in the elevation of hemoglobin gene expression in humans (Figure 1). ${ }^{40-42}$ Until recently, it was unclear which of the HIF and PHD isoforms regulated erythropoiesis and the expression of EPO in particular. Only with knowledge gained from patients with erythrocytosis and transgenic mice it became evident that the HIF2 $\alpha$ $\underline{\text { isoform and not HIF1 } \alpha \text { is the key player in EPO gene expression and erythropoiesis- }}$ enhancing processes (e.g. iron absorption and transport).

\section{Mutations in HIF pathway proteins can lead to erythrocytosis in humans}

Erythrocytosis is an aberrant increase in red blood cell number and comprises a heterogeneous group of disorders. A general distinction is made between the hypersensitivity of the erythroid progenitors to EPO (primary erythrocytosis) and the excessive activation of EPO gene transcription (secondary erythrocytosis). The most common example of primary erythrocytosis is Polycythemia Vera (PV). Here, erythroid progenitors carry a gain-offunction mutation in the $J A K 2$ gene, which leads to constitutive activation of the EPO signaling pathway at the EPO-R level. On the other hand, patients bearing point mutations in specific members of the HIF pathway can develop secondary erythrocytosis (Table 1).

\section{VHL}

In 1997, the first type of erythrocytosis related to the HIF pathway was discovered by Dr. Prchal and colleagues. They described 103 individuals suffering from erythrocytosis that belong to 81 families living in the Chuvash region (Russia). ${ }^{43} \mathrm{~A}$ number of patients were studied in detail and displayed markedly increased hematocrit levels accompanied by significantly higher EPO levels. However, molecular analysis failed to demonstrate mutations 
in the EPO-R or previously described erythrocyte alterations (e.g. high oxygen affinity hemoglobin). Subsequent genetic studies revealed a homozygous mutation in the $V H L$ gene (C598T leading to the R200W amino acid change) in all affected individuals. This resulted in reduced affinity of VHL for the hydroxylated HIF $\alpha$ subunit and subsequent increase of EPO and red blood cells. ${ }^{44,45}$ Recently, the underlying molecular mechanism was discovered: the R200W VHL mutation alters the affinity of VHL for suppression of cytokine signaling 1 (SOCS1), which prevents the degradation of the EPO-R coupled kinase pJAK2. ${ }^{46}$ This illustrates that VHL, as part of the oxygen sensing machinery, does not only influence the production of EPO but also regulates erythropoiesis at different levels. The clinical presentation of Chuvash erythrocytosis patients has been carefully studied and includes a wide range of hematological and vascular abnormalities but no tumors. Chuvash patients suffer from complications such as thrombosis, major bleeding episodes and higher systolic pulmonary artery pressure, which collectively lead to premature lethality. ${ }^{47-49}$ However, it has been suggested that thromboembolic events in patients with VHL mutations might be associated with a subsequent gain in HIF $\alpha$ activity rather than the increase in red blood cell mass. For instance, VEGF and PAI-1, two HIF $\alpha$ targets, are upregulated in the serum of Chuvash erythrocytosis patients, and might have an impact on coagulation pathways. ${ }^{50,51}$ Further studies have revealed higher homocysteine levels in Chuvash erythrocytosis patients, which could be an additional cause for the observed elevated blood pressure and thrombosis. ${ }^{52}$ Later, another cohort with the same mutation was identified on an island in the Bay of Naples, Italy, which suggested for a founder mutation. Indeed, single nucleotide polymorphism (SNP)-analysis near the VHL gene on individuals from different ethnic backgrounds confirmed this, indicating that the R200W mutation arose between 14,000 and 62,000 years ago in a single ancestor. ${ }^{53,54}$ Apart from the R200W mutation, two additional homozygous VHL mutations (Croatian H191D and P138L) and several (compound) heterozygous 
mutations have been discovered in single patients, resulting in very similar phenotypes observed in classical Chuvash patients. ${ }^{55-59}$ Conversely, the well-known autosomal dominant cancer-predisposition von Hippel-Lindau (VHL) syndrome, with over 1500 known VHL mutations, does not lead to erythrocytosis and is due to inheritance of a single mutated allele of VHL. ${ }^{60}$

\section{PHD2}

Since 2006, several patients and families with heterozygous loss-of-function mutations in the PHD2 gene have been described. ${ }^{55,61-64}$ The first mutations that were discovered are the P317R and the P371H variants, that affect the catalytic rate and substrate binding of PHD2, leading to partial inhibition of HIF hydroxylation. ${ }^{64-66}$ A few of the reported PHD2 mutations, apart from erythrocytosis, also led to other pathologies such as superficial thrombophlebitis ${ }^{64}$, sagittal sinus thrombosis ${ }^{66}$ and hypertension ${ }^{67}$. However, the number of such patients is currently still too small to draw firm conclusions. Only in one case, PHD2 has also been described to be associated with tumor formation - in particular, a recurrent paraganglioma. This patient is a heterozygous carrier of a PHD2 germline mutation (H374R) which affects one of the three conserved amino acids that coordinate $\mathrm{Fe}^{2+}$ binding, therefore contributing to the functionality of the enzyme. ${ }^{68}$ Interestingly, sequence analysis of the removed tumor mass showed that not one but both PHD2 alleles were mutated in the tumor cells (loss of heterozygosity). Functional analysis of the described PHD2 variants revealed that only the H374R variant has a detrimental effect, and all other studied PHD2 mutations show only weak deficiency in HIF $\alpha$ regulation. ${ }^{63}$ Such functional differences may permit PHD2 to act as a tumor suppressor in patients.

\section{HIF 2a}


A new form of familial erythrocytosis was discovered in a family where the phenotype was associated with a heterozygous missense mutation in the HIF2 $\alpha$ gene (EPAS1). The mutation is predicted to produce a G537W change in the amino acid sequence of HIF2 $\alpha$, which is very close to the primary site of hydroxylation (Pro-531). ${ }^{69}$ The resulting impairment of the hydroxylation of HIF2 $\alpha$ and its subsequent VHL binding leads to an aberrant stabilization of this transcription factor during normoxia. Further studies have revealed numerous other HIF $2 \alpha$ alterations, all near the primary hydroxylation site, typically leading to elevated EPO levels and erythrocytosis in the affected patients. ${ }^{55,70}$ In addition, numerous SNPs in the HIF $2 \alpha$ gene are found in Tibetans and are associated with only a moderate increase in hemoglobin concentrations. This adaptation to high altitude strengthens the link between HIF $2 \alpha$ and erythropoiesis. ${ }^{71,72}$ Contrarily, mutations of the HIF1 $\alpha$ isoform have not been associated with altered red blood cell production.

Interestingly, mutations of the HIF2 $\alpha$ gene have not only been shown to lead to erythrocytosis but have also been recently described to cause neoplasia. In particular, one patient carrying an inherited gain-of-function mutation in HIF2 $\alpha$ (F374Y) displayed erythrocytosis, with additional recurrent multiple paragangliomas. ${ }^{73}$ In addition, two erythrocytosis patients with paragangliomas, one of them with an additional somatostatinoma, have also been described to carry somatic HIF2 $\alpha$ mutations (A530T and A530V), which increase the half-life of the HIF $2 \alpha$ subunit and enhance HIF downstream signaling. ${ }^{74}$ The mutation was found in DNA from the tumor cells only and not in other cell types nor in the patients' parents, which argues for a causative postzygotic event. ${ }^{74}$ Screening of patients with chromaffin-cell tumors (paragangliomas, pheochromocytomas) led to the discovery of numerous other somatic HIF $2 \alpha$ mutations which are only partially accompanied by erythrocytosis. ${ }^{75-78}$ This predicts a direct oncogenic role for HIF2 $\alpha$, independent of its impact on red blood cell production. 
Taken together, patients bearing a polymorphism in VHL, PHD2 or HIF2 $\alpha$ collectively highlight the importance of the HIF signaling pathway in red blood cell homeostasis. Both somatic and germline mutations in HIF pathway members have been shown to lead to erythrocytosis. In some cases, erythrocytosis was accompanied by neuroendocrine tumors whose molecular basis remains to be unraveled (Table I).

\section{Genetically modified mice reveal important players in erythropoiesis}

Only a limited amount of erythrocytosis-associated mutations in the HIF pathway proteins in humans have been described so far - and most of them only very recently. To unravel the effective role of the different HIF pathway proteins during erythropoiesis, various genetically modified mice have been developed in the past 15 years (Table 2).

\section{HIFas, PHDs and VHL}

Although HIF1 $\alpha$ was initially discovered as the isoform that activates EPO transcription, ${ }^{5}$ it was only after both systemic and cell-type specific HIF1 $\alpha$ and HIF2 $\alpha$ knockout mice were made that the distinct role of both these transcription factors in erythropoiesis became clear. HIF $1 \alpha$ knockout mice (HIF $1 \alpha^{-/-}$) are only viable up to E11.5 and these embryos show major defects of the cardiovascular system and the neural tube. ${ }^{79,80}$ However, the lack of HIF1 $\alpha$ doesn't lead to complete abolishment of erythropoiesis, but rather to multiple disturbances in the adaptive responses to hypoxia. Conversely, HIF $2 \alpha$ deficient mice revealed that the observed pancytopenia is caused by abnormally low plasma EPO levels and impaired renal EPO induction. ${ }^{81}$ Ablation of this subunit after birth resulted in anemia accompanied by decreased circulatory EPO. ${ }^{82}$ Interestingly, even heterozygous deficient mice (HIF $2 \alpha^{+/}$) show a mild form of anemia (K.F. and B.W., unpublished data, October 21, 2011). The group of Dr. Haase was able to demonstrate that the regulation of erythropoiesis is essentially driven by 
renal HIF $2 \alpha{ }^{83}$ Indeed, specific deletion of HIF $2 \alpha$ in the kidney resulted in EPO-dependent anemia, which was only partially compensated by hepatic HIF $2{ }^{83}{ }^{83}$ Moreover, although both HIF isoforms are expressed in the kidney, only HIF $2 \alpha$ is found in the peritubular interstitial cells, ${ }^{32,74}$ and co-localized with EPO mRNA in these cells. ${ }^{84}$ At the molecular level, it was shown that HIF $2 \alpha$ is actually the major isoform binding the 3' enhancer of the EPO gene in its native form, whereas HIF1 $\alpha$ primarily binds to the isolated HRE, as initially described. ${ }^{4,5,85}$ Moreover, the existence of additional transcription factors that bind to sites outside the actual HRE which promote the preferential binding of HIF $2 \alpha$ has been proposed, too. ${ }^{85}$ Recently, the group of Dr. Lee presented a new mouse line bearing a G536W missense mutation in HIF2 $\alpha$ that corresponds to the first such human mutation identified (G537W). Remarkably, these mice not only showed elevated hematocrit and pulmonary hypertension, these findings attest that missense mutations in HIF2 $\alpha$ can indeed cause erythrocytosis. ${ }^{86}$

The HIF $\alpha$ subunits are regulated by different PHDs- the oxygen sensors. However, it is only after the mutant mouse lines were made that the functional differences between the family members became clear. Indeed, systemic deletion of PHD2, leads to embryonic lethality due to placental and heart defects, whereas PHD1 and PHD3-specific knockout mice do not show any apparent abnormalities. ${ }^{87}$ Inducible PHD2-deficient mice on the other hand, develop severe erythrocytosis and show decreased life expectancy. ${ }^{88,89}$ Mice that are systemically deficient for either PHD1 or PHD3 do not display increased hematocrit values, and only mice lacking both these isoforms simultaneously develop a moderate form of erythrocytosis. In the latter mice, plasma EPO and renal EPO expression is decreased while hepatic EPO mRNA is induced. ${ }^{89}$ Thus, PHD1 and PHD3 appear to have only minor roles in the regulation of EPO expression, although their additional loss in the background of PHD2-deficiency can ameliorate the erythrocytosis phenotype. ${ }^{90,91}$ Our research group recently developed a 
conditional PHD2-deficient mouse line displaying severe but non-lethal erythrocytosis. ${ }^{92}$ Using different genetic approaches (PHD2/HIF $\alpha$ double deficient mice) we could show that the EPO-dependent red blood cell increase is driven by HIF2 $\alpha$, which is in line with other observations made in familial erythrocytosis. ${ }^{69,93}$ Conversely, we found that HIF $1 \alpha$ actually serves as a protective factor in these PHD2-deficient mice via the local induction of PHD3. ${ }^{92}$

Mice carrying a homozygous deletion of the VHL gene die in utero due to a defect in placental vasculogenesis. ${ }^{94}$ A liver specific VHL deletion led to hepatic vascular tumors and erythrocytosis, which was accompanied by increased EPO levels. ${ }^{95}$ The increase in erythrocytes was not reversible by additional hepatic HIF1 $\alpha$ deletion, ${ }^{96}$ but only by deletion of HIF $2 \alpha{ }^{85}$ Mice with an astrocyte specific deletion of VHL not only exhibit a significant increase in cerebral EPO mRNA but also a significant induction of plasma EPO and erythrocytosis. ${ }^{16}$ The additional deletion of HIF $1 \alpha$ did not correct this increase in red blood cell count but rather made the phenotype more severe and shortened the survival time of these double deficient mice. On the other hand, elimination of HIF2 $\alpha$ along with VHL normalized the red blood cell count and most of the cerebral EPO transcript. ${ }^{16}$ Recently, ablation of VHL in osteoblasts led to HIF2 $\alpha$-dependent EPO induction in these cells, accompanied by erythrocytosis and enhanced bone formation. ${ }^{97}$ In 2007, a mouse line carrying the homozygous R200W mutation (leading to Chuvash erythrocytosis in humans) was created. Interestingly, this point mutation resulted in moderate erythrocytosis accompanied by splenic erythropoiesis. ${ }^{98}$ Embryonic stem cells carrying this mutation exhibited normoxic stabilization of HIF $2 \alpha$, which was accompanied by up-regulation of HIF2 $\alpha$-targets like VEGF.

\section{Conclusion}


Deregulation of EPO transcription due to mutations in HIF pathway proteins is an important underlying cause of erythrocytosis in patients. Moreover, these mutations can also result in other pathologies like tumor development. Recently, various point-mutations in the $H I F 2 \alpha / E P A S 1, V H L$ and PHD2 genes have been identified and additional studies have led to new insights into the HIF pathway. Complementary to these mutations, many genetically modified mice have provided a powerful tool to study the effect and location of HIF pathway members in relation to erythropoiesis and additional risk factors. Furthermore, it might be of great interest to develop new mouse models for erythrocytosis and related diseases including mice carrying specific point mutations found in humans (as mentioned above for the R200W VHL and very recently the G537W HIF2 $\alpha$ mutation).

\section{Acknowledgements}

We thank the entire Wielockx lab for helpful discussions and Dr. Soulafa Mamlouk and Dr. Vasuprada Iyengar in particular for critical reading of the manuscript. B.W. is an Emmy Noether research fellow (DFG). Work in the lab of Ben Wielockx has been supported by grants from the MeDDrive-Programm (TU Dresden, Germany) and the DFG (WI 3291/1-1 and 1-2). Work in the lab of Max Gassmann has been supported by the Swiss National Science Foundation. This review is a collaborative work within the COST Action TD0901 "HypoxiaNet". We apologize to our colleagues whose work was not cited due to space limitations.

\section{Author contribution}

K.F. and B.W. wrote the manuscript. M.G. provided helpful discussions and helped write the manuscript.

\section{Conflict of interest}


The authors declare that there are no competing financial interests. 


\section{References}

1. Jourdanet D. Influence de la Pression de L'air sur la Vie de L'homme. Paris: Masson. 1875.

2. Miyake T, Kung CK, Goldwasser E. Purification of human erythropoietin. $J$ Biol Chem. 1977;252(15):5558-5564.

3. Jacobs K, Shoemaker C, Rudersdorf R, et al. Isolation and characterization of genomic and cDNA clones of human erythropoietin. Nature. 1985;313(6005):806-810.

4. Semenza GL, Wang GL. A nuclear factor induced by hypoxia via de novo protein synthesis binds to the human erythropoietin gene enhancer at a site required for transcriptional activation. Mol Cell Biol. 1992;12(12):5447-5454.

5. Wang GL, Jiang BH, Rue EA, Semenza GL. Hypoxia-inducible factor 1 is a basichelix-loop-helix-PAS heterodimer regulated by cellular O2 tension. Proc Natl Acad Sci US A. 1995;92(12):5510-5514.

6. Wang GL, Semenza GL. General involvement of hypoxia-inducible factor 1 in transcriptional response to hypoxia. Proc Natl Acad Sci U S A. 1993;90(9):4304-4308.

7. Firth JD, Ebert BL, Pugh CW, Ratcliffe PJ. Oxygen-regulated control elements in the phosphoglycerate kinase 1 and lactate dehydrogenase A genes: similarities with the erythropoietin 3' enhancer. Proc Natl Acad Sci U S A. 1994;91(14):6496-6500.

8. Nagao M, Ebert BL, Ratcliffe PJ, Pugh CW. Drosophila melanogaster SL2 cells contain a hypoxically inducible DNA binding complex which recognises mammalian HIFbinding sites. FEBS Lett. 1996;387(2-3):161-166.

9. Jacobson LO, Goldwasser E, Fried W, Plzak L. Role of the kidney in erythropoiesis. Nature. 1957;179(4560):633-634.

10. Koury ST, Bondurant MC, Koury MJ. Localization of erythropoietin synthesizing cells in murine kidneys by in situ hybridization. Blood. 1988;71(2):524-527.

11. Koury ST, Koury MJ, Bondurant MC, Caro J, Graber SE. Quantitation of erythropoietin-producing cells in kidneys of mice by in situ hybridization: correlation with hematocrit, renal erythropoietin mRNA, and serum erythropoietin concentration. Blood. 1989;74(2):645-651.

12. Bachmann S, Hir ML, Eckardt KU. Co-localization of erythropoietin mRNA and ecto5 '-nucleotidase immunoreactivity in peritubular cells of rat renal cortex indicates that fibroblasts produce erythropoietin. J Histochem Cytochem. 1993;41(3):335-341.

13. Maxwell PH, Osmond MK, Pugh CW, et al. Identification of the renal erythropoietinproducing cells using transgenic mice. Kidney Int. 1993;44(5):1149-1162.

14. Obara N, Suzuki N, Kim K, Nagasawa T, Imagawa S, Yamamoto M. Repression via the GATA box is essential for tissue-specific erythropoietin gene expression. Blood. 2008;111(10):5223-5232.

15. Marti HH, Wenger RH, Rivas LA, et al. Erythropoietin gene expression in human, monkey and murine brain. Eur J Neurosci. 1996;8(4):666-676.

16. Weidemann A, Kerdiles YM, Knaup KX, et al. The glial cell response is an essential component of hypoxia-induced erythropoiesis in mice. J Clin Invest. 2009;119(11):33733383.

17. Sakanaka M, Wen TC, Matsuda S, et al. In vivo evidence that erythropoietin protects neurons from ischemic damage. Proc Natl Acad Sci U S A. 1998;95(8):4635-4640.

18. Soliz J, Joseph V, Soulage C, et al. Erythropoietin regulates hypoxic ventilation in mice by interacting with brainstem and carotid bodies. $J$ Physiol. 2005;568(Pt 2):559-571. 
19. Miskowiak K, Inkster B, Selvaraj S, Wise R, Goodwin GM, Harmer CJ. Erythropoietin improves mood and modulates the cognitive and neural processing of emotion 3 days post administration. Neuropsychopharmacology. 2008;33(3):611-618.

20. Richmond TD, Chohan M, Barber DL. Turning cells red: signal transduction mediated by erythropoietin. Trends Cell Biol. 2005;15(3):146-155.

21. Hattangadi SM, Wong P, Zhang L, Flygare J, Lodish HF. From stem cell to red cell: regulation of erythropoiesis at multiple levels by multiple proteins, RNAs, and chromatin modifications. Blood. 2011;118(24):6258-6268.

22. Bauer A, Tronche F, Wessely $\mathrm{O}$, et al. The glucocorticoid receptor is required for stress erythropoiesis. Genes Dev. 1999;13(22):2996-3002.

23. Broudy VC, Lin NL, Priestley GV, Nocka K, Wolf NS. Interaction of stem cell factor and its receptor c-kit mediates lodgment and acute expansion of hematopoietic cells in the murine spleen. Blood. 1996;88(1):75-81.

24. Lenox LE, Perry JM, Paulson RF. BMP4 and Madh5 regulate the erythroid response to acute anemia. Blood. 2005;105(7):2741-2748.

25. Ramos P, Casu C, Gardenghi S, et al. Macrophages support pathological erythropoiesis in polycythemia vera and beta-thalassemia. Nat Med. 2013.

26. Jewell UR, Kvietikova I, Scheid A, Bauer C, Wenger RH, Gassmann M. Induction of HIF-1alpha in response to hypoxia is instantaneous. FASEB J. 2001;15(7):1312-1314.

27. Fandrey J, Gorr TA, Gassmann M. Regulating cellular oxygen sensing by hydroxylation. Cardiovasc Res. 2006;71(4):642-651.

28. Xia X, Lemieux $\mathrm{ME}, \mathrm{Li} \mathrm{W}$, et al. Integrative analysis of HIF binding and transactivation reveals its role in maintaining histone methylation homeostasis. Proc Natl Acad Sci U S A. 2009;106(11):4260-4265.

29. Schodel J, Oikonomopoulos S, Ragoussis J, Pugh CW, Ratcliffe PJ, Mole DR. Highresolution genome-wide mapping of HIF-binding sites by ChIP-seq. Blood. 2011;117(23):e207-217.

30. Ivan M, Kondo K, Yang H, et al. HIFalpha targeted for VHL-mediated destruction by proline hydroxylation: implications for O2 sensing. Science. 2001;292(5516):464-468.

31. Jaakkola P, Mole DR, Tian YM, et al. Targeting of HIF-alpha to the von HippelLindau ubiquitylation complex by O2-regulated prolyl hydroxylation. Science. 2001;292(5516):468-472.

32. Epstein AC, Gleadle JM, McNeill LA, et al. C. elegans EGL-9 and mammalian homologs define a family of dioxygenases that regulate HIF by prolyl hydroxylation. Cell. 2001;107(1):43-54.

33. Berra E, Benizri E, Ginouvès A, Volmat V, Roux D, Pouysségur J. HIF prolylhydroxylase 2 is the key oxygen sensor setting low steady-state levels of HIF-1alpha in normoxia. EMBO J. 2003;22(16):4082-4090.

34. Oehme F, Ellinghaus P, Kolkhof P, et al. Overexpression of PH-4, a novel putative proline 4-hydroxylase, modulates activity of hypoxia-inducible transcription factors. Biochem Biophys Res Commun. 2002;296(2):343-349.

35. Wiesener MS, Jürgensen JS, Rosenberger C, et al. Widespread hypoxia-inducible expression of HIF-2alpha in distinct cell populations of different organs. FASEB J. $2003 ; 17(2): 271-273$.

36. Hu C-J, Wang L-Y, Chodosh LA, Keith B, Simon MC. Differential roles of hypoxiainducible factor 1alpha (HIF-1alpha) and HIF-2alpha in hypoxic gene regulation. Mol Cell Biol. 2003;23(24):9361-9374.

37. van Patot MC, Gassmann M. Hypoxia: adapting to high altitude by mutating EPAS-1, the gene encoding HIF-2alpha. High Alt Med Biol. 2011;12(2):157-167. 
38. Branco-Price C, Zhang N, Schnelle M, et al. Endothelial cell HIF-1alpha and HIF2alpha differentially regulate metastatic success. Cancer Cell. 2012;21(1):52-65.

39. Raval RR, Lau KW, Tran MGB, et al. Contrasting properties of hypoxia-inducible factor 1 (HIF-1) and HIF-2 in von Hippel-Lindau-associated renal cell carcinoma. Mol Cell Biol. 2005;25(13):5675-5686.

40. Petrella BL, Lohi J, Brinckerhoff CE. Identification of membrane type-1 matrix metalloproteinase as a target of hypoxia-inducible factor-2 alpha in von Hippel-Lindau renal cell carcinoma. Oncogene. 2005;24(6):1043-1052.

41. Covello KL, Kehler J, Yu H, et al. HIF-2alpha regulates Oct-4: effects of hypoxia on stem cell function, embryonic development, and tumor growth. Genes Dev. 2006;20(5):557570.

42. Chen F, Zhang W, Liang Y, et al. Transcriptome and network changes in climbers at extreme altitudes. PLoS One. 2012;7(2):e31645.

43. Sergeyeva A, Gordeuk VR, Tokarev YN, Sokol L, Prchal JF, Prchal JT. Congenital polycythemia in Chuvashia. Blood. 1997;89(6):2148-2154.

44. Ang SO, Chen H, Gordeuk VR, et al. Endemic polycythemia in Russia: mutation in the VHL gene. Blood Cells Mol Dis. 2002;28(1):57-62.

45. Ang SO, Chen $\mathrm{H}$, Hirota $\mathrm{K}$, et al. Disruption of oxygen homeostasis underlies congenital Chuvash polycythemia. Nat Genet. 2002;32(4):614-621.

46. Russell RC, Sufan RI, Zhou B, et al. Loss of JAK2 regulation via a heterodimeric VHL-SOCS1 E3 ubiquitin ligase underlies Chuvash polycythemia. Nat Med. 2011;17(7):845853.

47. Bushuev VI, Miasnikova GY, Sergueeva AI, et al. Endothelin-1, vascular endothelial growth factor and systolic pulmonary artery pressure in patients with Chuvash polycythemia. Haematologica. 2006;91(6):744-749.

48. Gordeuk VR, Sergueeva AI, Miasnikova GY, et al. Congenital disorder of oxygen sensing: association of the homozygous Chuvash polycythemia VHL mutation with thrombosis and vascular abnormalities but not tumors. Blood. 2004;103(10):3924-3932.

49. Sable CA, Aliyu ZY, Dham N, et al. Pulmonary artery pressure and iron deficiency in patients with upregulation of hypoxia sensing due to homozygous VHL(R200W) mutation (Chuvash polycythemia). Haematologica. 2012;97(2):193-200.

50. Gordeuk VR, Prchal JT. Vascular complications in Chuvash polycythemia. Semin Thromb Hemost. 2006;32(3):289-294.

51. Liu X, Hao L, Zhang S, et al. Genetic repression of mouse VEGF expression regulates coagulation cascade. IUBMB Life. 2010;62(11):819-824.

52. Sergueeva AI, Miasnikova GY, Okhotin DJ, et al. Elevated homocysteine, glutathione and cysteinylglycine concentrations in patients homozygous for the Chuvash polycythemia VHL mutation. Haematologica. 2008;93(2):279-282.

53. Perrotta S, Nobili B, Ferraro M, et al. Von Hippel-Lindau-dependent polycythemia is endemic on the island of Ischia: identification of a novel cluster. Blood. 2006;107(2):514-519.

54. Liu E, Percy MJ, Amos CI, et al. The worldwide distribution of the VHL 598C $>$ T mutation indicates a single founding event. Blood. 2004;103(5):1937-1940.

55. Lee FS, Percy MJ. The HIF pathway and erythrocytosis. Annu Rev Pathol. 2011;6:165-192.

56. Bond J, Gale DP, Connor T, et al. Dysregulation of the HIF pathway due to VHL mutation causing severe erythrocytosis and pulmonary arterial hypertension. Blood. 2011;117(13):3699-3701.

57. Lanikova L, Lorenzo F, Yang C, et al. Novel homozygous VHL mutation in exon 2 is associated with congenital polycythemia but not with cancer. Blood. 2013. 
58. Tomasic NL, Piterkova L, Huff C, et al. The phenotype of polycythemia due to Croatian homozygous VHL (571C $>$ G:H191D) mutation is different from that of Chuvash polycythemia (VHL 598C>T:R200W). Haematologica. 2013;98(4):560-567.

59. Pastore Y, Jedlickova K, Guan Y, et al. Mutations of von Hippel-Lindau tumorsuppressor gene and congenital polycythemia. Am J Hum Genet. 2003;73(2):412-419.

60. Nordstrom-O'Brien M, van der Luijt RB, van Rooijen E, et al. Genetic analysis of von Hippel-Lindau disease. Hum Mutat. 2010;31(5):521-537.

61. Albiero E, Ruggeri M, Fortuna S, et al. Analysis of the oxygen sensing pathway genes in familial chronic myeloproliferative neoplasms and identification of a novel EGLN1 germline mutation. Br J Haematol. 2011;153(3):405-408.

62. Albiero E, Ruggeri M, Fortuna S, et al. Isolated erythrocytosis: study of 67 patients and identification of three novel germ-line mutations in the prolyl hydroxylase domain protein 2 (PHD2) gene. Haematologica. 2012;97(1):123-127.

63. Ladroue C, Hoogewijs D, Gad S, et al. Distinct deregulation of the hypoxia inducible factor by PHD2 mutants identified in germline DNA of patients with polycythemia. Haematologica. 2012;97(1):9-14.

64. Percy MJ, Zhao Q, Flores A, et al. A family with erythrocytosis establishes a role for prolyl hydroxylase domain protein 2 in oxygen homeostasis. Proc Natl Acad Sci US A. 2006;103(3):654-659.

65. Pappalardi MB, Martin JD, Jiang Y, et al. Biochemical characterization of human prolyl hydroxylase domain protein 2 variants associated with erythrocytosis. Biochemistry. 2008;47(43):11165-11167.

66. Percy MJ, Furlow PW, Beer PA, Lappin TRJ, McMullin MF, Lee FS. A novel erythrocytosis-associated PHD2 mutation suggests the location of a HIF binding groove. Blood. 2007;110(6):2193-2196.

67. Al-Sheikh M, Moradkhani K, Lopez M, Wajcman H, Préhu C. Disturbance in the HIF1alpha pathway associated with erythrocytosis: further evidences brought by frameshift and nonsense mutations in the prolyl hydroxylase domain protein 2 (PHD2) gene. Blood Cells Mol Dis. 2008;40(2):160-165.

68. Ladroue C, Carcenac R, Leporrier $\mathrm{M}$, et al. PHD2 mutation and congenital erythrocytosis with paraganglioma. N Engl J Med. 2008;359(25):2685-2692.

69. Percy MJ, Furlow PW, Lucas GS, et al. A gain-of-function mutation in the HIF2A gene in familial erythrocytosis. $N$ Engl J Med. 2008;358(2):162-168.

70. Percy MJ, Chung YJ, Harrison C, et al. Two new mutations in the HIF2A gene associated with erythrocytosis. Am J Hematol. 2012.

71. Beall CM, Cavalleri GL, Deng L, et al. Natural selection on EPAS1 (HIF2alpha) associated with low hemoglobin concentration in Tibetan highlanders. Proc Natl Acad Sci US A. 2010;107(25):11459-11464.

72. Simonson TS, Yang Y, Huff CD, et al. Genetic evidence for high-altitude adaptation in Tibet. Science. 2010;329(5987):72-75.

73. Lorenzo FR, Yang $\mathrm{C}$, Ng Tang Fui $\mathrm{M}$, et al. A novel EPAS1/HIF2A germline mutation in a congenital polycythemia with paraganglioma. $J$ Mol Med (Berl). 2013;91(4):507-512.

74. Zhuang Z, Yang C, Lorenzo F, et al. Somatic HIF2A gain-of-function mutations in paraganglioma with polycythemia. $N$ Engl J Med. 2012;367(10):922-930.

75. Yang C, Sun MG, Matro J, et al. Novel HIF2A mutations disrupt oxygen sensing, leading to polycythemia, paragangliomas, and somatostatinomas. Blood. 2013;121(13):25632566 . 
76. Comino-Mendez I, de Cubas AA, Bernal C, et al. Tumoral EPAS1 (HIF2A) mutations explain sporadic pheochromocytoma and paraganglioma in the absence of erythrocytosis. Hum Mol Genet. 2013.

77. Taieb D, Yang C, Delenne B, et al. First Report of Bilateral Pheochromocytoma in the Clinical Spectrum of HIF2A-Related Polycythemia-Paraganglioma Syndrome. J Clin Endocrinol Metab. 2013.

78. Toledo RA, Qin Y, Srikantan S, et al. In vivo and in vitro oncogenic effects of HIF2A mutations in pheochromocytomas and paragangliomas. Endocr Relat Cancer. 2013.

79. Iyer NV, Kotch LE, Agani F, et al. Cellular and developmental control of O2 homeostasis by hypoxia-inducible factor 1 alpha. Genes Dev. 1998;12(2):149-162.

80. Ryan HE, Lo J, Johnson RS. HIF-1 alpha is required for solid tumor formation and embryonic vascularization. EMBO J. 1998;17(11):3005-3015.

81. Scortegagna M, Ding K, Zhang Q, et al. HIF-2alpha regulates murine hematopoietic development in an erythropoietin-dependent manner. Blood. 2005;105(8):3133-3140.

82. Gruber M, Hu C-J, Johnson RS, Brown EJ, Keith B, Simon MC. Acute postnatal ablation of Hif-2alpha results in anemia. Proc Natl Acad Sci U S A. 2007;104(7):2301-2306.

83. Kapitsinou PP, Liu Q, Unger TL, et al. Hepatic HIF-2 regulates erythropoietic responses to hypoxia in renal anemia. Blood. 2010;116(16):3039-3048.

84. Paliege A, Rosenberger C, Bondke A, et al. Hypoxia-inducible factor-2alphaexpressing interstitial fibroblasts are the only renal cells that express erythropoietin under hypoxia-inducible factor stabilization. Kidney Int. 2010;77(4):312-318.

85. Rankin EB, Biju MP, Liu Q, et al. Hypoxia-inducible factor-2 (HIF-2) regulates hepatic erythropoietin in vivo. J Clin Invest. 2007;117(4):1068-1077.

86. Tan Q, Kerestes H, Percy MJ, et al. Erythrocytosis and Pulmonary Hypertension in a Mouse Model of Human HIF2A Gain-of-Function Mutation. J Biol Chem. 2013.

87. Takeda K, Ho VC, Takeda H, Duan L-J, Nagy A, Fong G-H. Placental but not heart defects are associated with elevated hypoxia-inducible factor alpha levels in mice lacking prolyl hydroxylase domain protein 2. Mol Cell Biol. 2006;26(22):8336-8346.

88. Minamishima YA, Moslehi J, Bardeesy N, Cullen D, Bronson RT, Kaelin WG. Somatic inactivation of the PHD2 prolyl hydroxylase causes polycythemia and congestive heart failure. Blood. 2008;111(6):3236-3244.

89. Takeda K, Aguila HL, Parikh NS, et al. Regulation of adult erythropoiesis by prolyl hydroxylase domain proteins. Blood. 2008;111(6):3229-3235.

90. Minamishima YA, Moslehi J, Padera RF, Bronson RT, Liao R, Kaelin WG. A feedback loop involving the Phd3 prolyl hydroxylase tunes the mammalian hypoxic response in vivo. Mol Cell Biol. 2009;29(21):5729-5741.

91. Minamishima YA, Kaelin WG. Reactivation of hepatic EPO synthesis in mice after PHD loss. Science. 2010;329(5990):407.

92. Franke K, Kalucka J, Mamlouk S, et al. HIF-1alpha is a protective factor in conditional PHD2-deficient mice suffering from severe HIF-2alpha-induced excessive erythropoiesis. Blood. 2013;121(8):1436-1445.

93. Percy MJ, Beer PA, Campbell G, et al. Novel exon 12 mutations in the HIF2A gene associated with erythrocytosis. Blood. 2008;111(11):5400-5402.

94. Gnarra JR, Ward JM, Porter FD, et al. Defective placental vasculogenesis causes embryonic lethality in VHL-deficient mice. Proc Natl Acad Sci U S A. 1997;94(17):91029107.

95. Haase VH, Glickman JN, Socolovsky M, Jaenisch R. Vascular tumors in livers with targeted inactivation of the von Hippel-Lindau tumor suppressor. Proc Natl Acad Sci U S A. 2001;98(4):1583-1588. 
96. Rankin EB, Higgins DF, Walisser JA, Johnson RS, Bradfield CA, Haase VH. Inactivation of the arylhydrocarbon receptor nuclear translocator (Arnt) suppresses von Hippel-Lindau disease-associated vascular tumors in mice. Mol Cell Biol. 2005;25(8):31633172.

97. Rankin EB, Wu C, Khatri R, et al. The HIF Signaling Pathway in Osteoblasts Directly Modulates Erythropoiesis through the Production of EPO. Cell. 2012;149(1):63-74.

98. Hickey MM, Lam JC, Bezman NA, Rathmell WK, Simon MC. von Hippel-Lindau mutation in mice recapitulates Chuvash polycythemia via hypoxia-inducible factor-2alpha signaling and splenic erythropoiesis. J Clin Invest. 2007;117(12):3879-3889.

99. Mazzone M, Dettori D, de Oliveira RL, et al. Heterozygous deficiency of PHD2 restores tumor oxygenation and inhibits metastasis via endothelial normalization. Cell. 2009;136(5):839-851.

100. Scortegagna M, Ding K, Oktay Y, et al. Multiple organ pathology, metabolic abnormalities and impaired homeostasis of reactive oxygen species in Epas1-/- mice. Nat Genet. 2003;35(4):331-340. 
Figure 1: Oxygen-dependent regulation of HIF $\alpha$ and its target genes. If oxygen demand is covered, HIF $\alpha$ becomes constantly hydroxylated by PHDs, and subsequently undergoes proteasomal degradation after binding with VHL. Under hypoxic conditions, HIF $\alpha$ is stabilized, translocates to the nucleus, binds to its heterodimerization partner HIF $\beta$ as well as to other co-factors, and leads to the transcriptional activation of target genes that harbor HRE sequences in their promoter region. HIF $1 \alpha$ and HIF2 $\alpha$ share target genes (green) but have certain preferences (preferentially induced by HIF1 $\alpha$ in yellow; by HIF2 $\alpha$ in blue) (HIF: hypoxia inducible factor, PHD: prolyl hydroxylase, VHL: von Hippel-lindau, CBP: CREBbinding protein, HRE: hypoxia responsive element). 
Table 1: HIF pathway related mutations that have resulted in erythrocytosis and/or tumor development in humans.

\begin{tabular}{|c|c|c|c|c|c|}
\hline Gene & Type of mutation & mutation & erythrocytosis & Tumor type & Ref. \\
\hline \multirow[t]{4}{*}{ VHL } & $\begin{array}{c}\text { Germline } \\
\text { (Homo }>>\text { Hetero) }\end{array}$ & R200W & + & - & 45,55 \\
\hline & Germline (Homo) & $\begin{array}{l}\text { H191D } \\
\text { P138L }\end{array}$ & + & - & $57-59$ \\
\hline & $\begin{array}{c}\text { Germline } \\
\text { ((Compound) Hetero) }\end{array}$ & $\begin{array}{c}\text { Various } \\
\text { (including } \\
\text { R200W) }\end{array}$ & + & - & 55,56 \\
\hline & $\begin{array}{c}\text { Somatic/ } \\
\text { Germline (Hetero) }\end{array}$ & various & - & $\begin{array}{l}\text { e.g. spinal } \\
\text { hemangioblastoma, } \\
\text { renal cell carcinoma } \\
\text { (RCC) and } \\
\text { pheochromocytoma }\end{array}$ & 60 \\
\hline \multirow[t]{2}{*}{ PHD2 } & Germline (Hetero) & various & + & - & $\begin{array}{c}55,61- \\
64,66,67\end{array}$ \\
\hline & Germline (Hetero) & H374R & + & paraganglioma & 68 \\
\hline \multirow[t]{4}{*}{ HIF $2 \alpha$} & Germline (Hetero) & $\begin{array}{c}\text { Various } \\
\text { (including } \\
\text { G537W) }\end{array}$ & + & - & $55,69,70$ \\
\hline & Germline (Hetero) & F374Y & + & $\begin{array}{c}\text { pheochromocytoma/ } \\
\text { paraganglioma }\end{array}$ & 73 \\
\hline & Somatic (Hetero) & $\begin{array}{l}\text { A530V } \\
\text { A530T }\end{array}$ & + & $\begin{array}{l}\text { paragangliomas/ } \\
\text { somatostatinoma }\end{array}$ & 74 \\
\hline & Somatic (Hetero) & various & $+/-$ & $\begin{array}{c}\text { Pheochromocytomas } \\
\text { / paragangliomas / } \\
\text { somatostatinoma }\end{array}$ & $75-78$ \\
\hline
\end{tabular}


Table 2: Available genetically modified mice illustrating the impact of a deregulated HIF system on murine erythropoiesis.

* in anemic mice and during early postnatal development

\begin{tabular}{|c|c|c|c|}
\hline Gene & Type of modification & Phenotype mice & Ref. \\
\hline VHL & Liver specific KO & erythrocytosis & 95 \\
\hline \multirow{2}{*}{ PHD2 } & Brain specific KO & erythrocytosis & 16 \\
\hline \multirow{2}{*}{ R200W mutation } & erythrocytosis & 98 \\
\hline \multirow{2}{*}{ HIF2 $\alpha$} & $\begin{array}{c}\text { Conditional KO (including EPO- } \\
\text { producing cells in kidney and brain) }\end{array}$ & erythrocytosis & 92 \\
\hline \multirow{2}{*}{ Heterozygosity } & mild erythrocytosis & 99 \\
\hline & Complete KO & pancytopenia & 100 \\
\hline & Induced complete KO & anemia & 82 \\
\hline & Liver specific KO & anemia & $* 85$ \\
& Kidney specific KO & anemia & 83 \\
\hline & Heterozygosity & mild anemia & unpublished \\
\hline & erythrocytosis & 86 \\
\hline
\end{tabular}


Figure 1

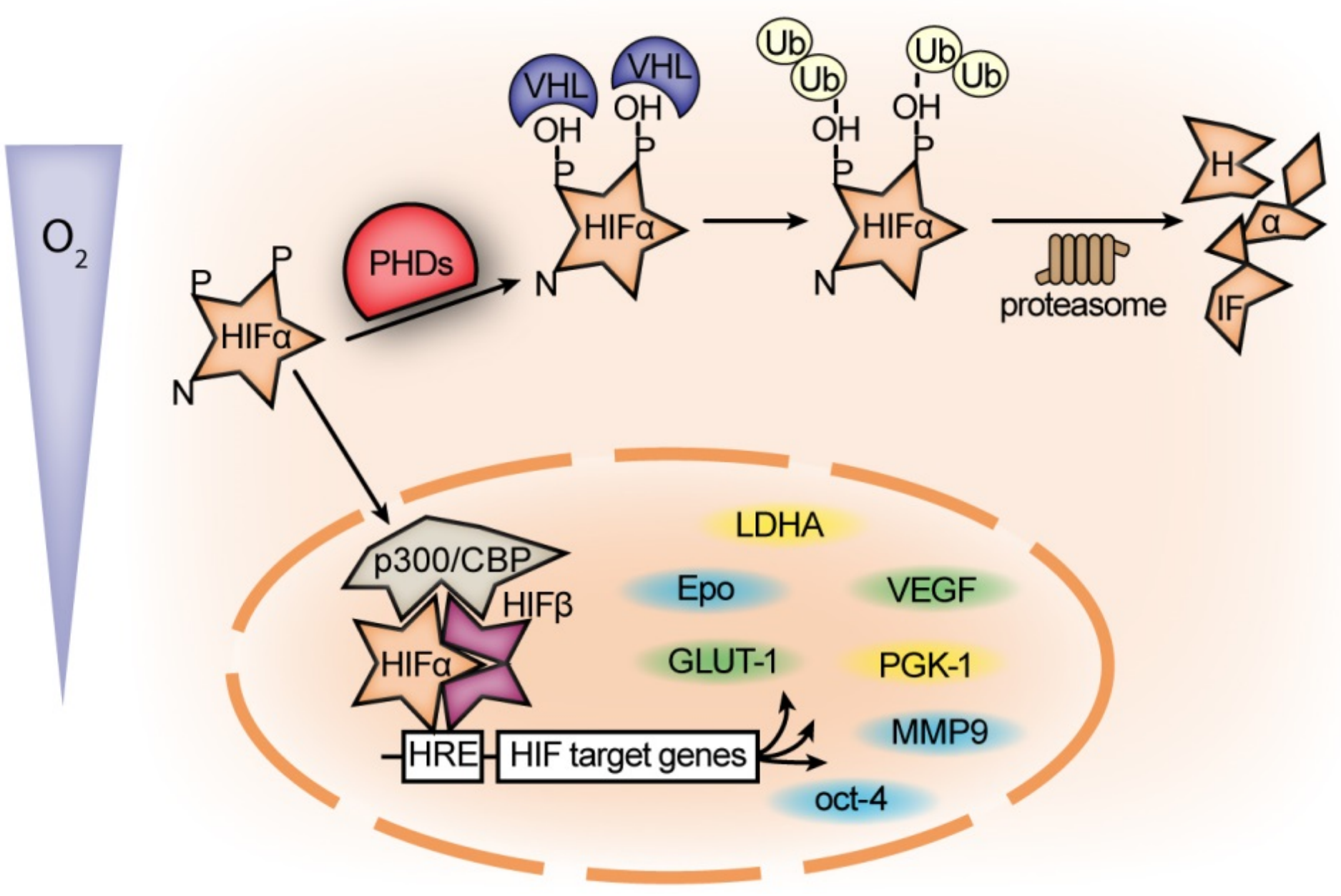

